\title{
Morphometric variation in red-spot prawn (Metapenaeopsis barbata) in different geographic waters off Taiwan
}

\author{
Tzong-Der Tzeng, Chin-Shiang Chiu, Shean-Ya Yeh* \\ Institute of Oceanography, National Taiwan University, Taipei 106, Taiwan, ROC
}

Received 6 June 2000; received in revised form 19 September 2000; accepted 21 November 2000

\begin{abstract}
Morphometric variation was used to elucidate the stock structure of red-spot prawn (Metapenaeopsis barbata) in adjacent waters off Taiwan. Five samples were separately collected from Keelung, Tashi, Taichung, Putai, and Cheding. The 10 measurements made for each individual were size-standardized by Burnaby's method and resulting measurements submitted to canonical variate analysis; the square of Manhattan distance (Manhattan $D^{2}$ ) between population centroids values were then calculated using canonical scores. Dendrograms were constructed by three different clustering methods using Manhattan $D^{2}$ values. A randomization test was used to test the significance of morphometric variation between different groups derived from cluster analysis. A sexual dimorphism for red-spot prawn was found by ANCOVA, so analyses were separately performed by sex. Five sampling areas were clustered into two groups by each sex, the first group included Keelung; the second group included Tashi, Taichung, Putai, and Cheding. Randomization tests showed that morphometric variation between these two groups was significant for each sex. There appear to be at least two morphologically distinguishable stocks of redspot prawn in adjacent waters off Taiwan. The utility of morphometric measurements for discriminating stock of red-spot prawn is demonstrated, but further verification of the stock structure may be essential. (C) 2001 Elsevier Science B.V. All rights reserved.
\end{abstract}

Keywords: Stock discrimination; Morphometric comparison; Metapenaeopsis barbata

\section{Introduction}

Red-spot prawn (Metapenaeopsis barbata) is an abundant and widely distributed demersal species in the East China Sea and Taiwan Strait (Wu, 1984). Several studies on the fishery biology of this species have been conducted in Taiwan (Wu, 1984;

\footnotetext{
* Corresponding author. Tel.: +886-223-637753; fax: +886-223-661197.

E-mail address: sheanya@ccms.ntu.edu.tw (S.-Y. Yeh).
}

Tzeng and Yeh, 1995; Tzeng et al., 1998), but stock structure of red-spot prawn has still not been fully developed.

Concrete information on stock structure is essential for rational exploitation and management. Various methods have been proved powerful tools for studying stock structure, such as morphometric comparison, protein electrophoresis, or nucleotide sequence analysis (Moritz et al., 1987; Shaklee et al., 1982; Tzeng and Yeh, 1999a).

Morphometric variability between different geographical populations may be attributable to distinct 
genetic structure and environmental conditions (Waldman et al., 1988). Therefore, animals with the same morphometric characters are often assumed to constitute a stock, and that has been utilized widely in fishery stock differentiation studies (Avsar, 1994).

Morphometric data describing body form should be compared with shape variates that are free from the effect of size variation (Reist, 1985). Several size correction techniques are available to obtain size-free morphometric data, including regression techniques (Reist, 1985), shearing PCA (Humphries et al., 1981), multiple group PCA (Thorpe, 1983), and Burnaby's method (Burnaby, 1966).

The objective of our study was to examine the extent of morphometric variability among different populations of red-spot prawn in adjacent waters off
Taiwan, using a multivariate method to elucidate the existence of different stocks.

\section{Materials and methods}

Five samples were separately collected from adjacent waters off Tashi, Taichung, Putai, Cheding, and Keelung (Fig. 1) during November and December in 1995. Sex was identified and individual separated accordingly. Ten measurements were made on each specimen (Fig. 2): antennal spine width (ASW), hepatic spine width (HSW), carapace length (CL), diagonal carapace length (DCL), first abdominal segment length (FSL), first abdominal segment width (FSW), first abdominal segment height (FSH), second abdominal

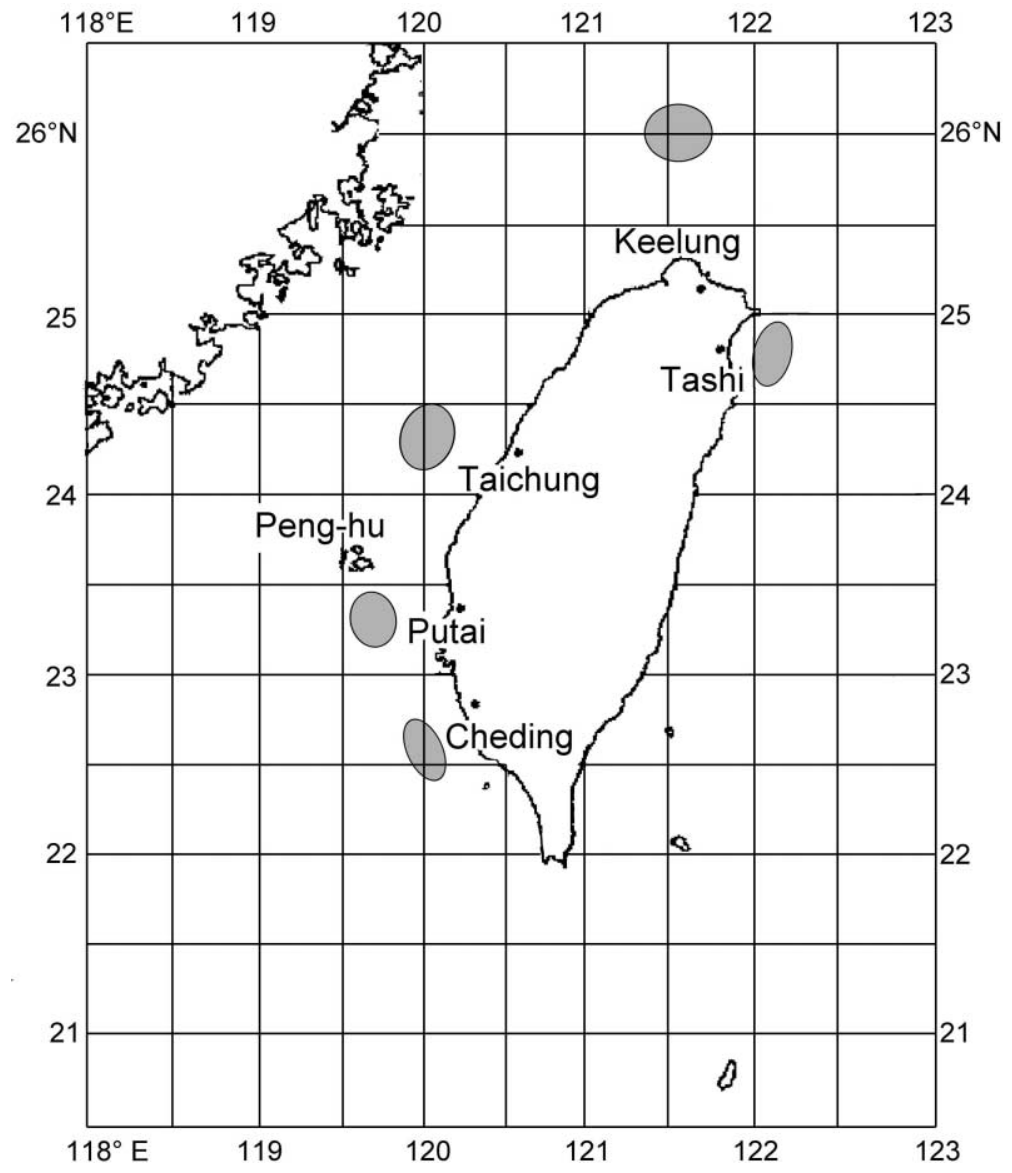

Fig. 1. Shadowed areas showing the areas sampled from adjacent waters off Taiwan. 


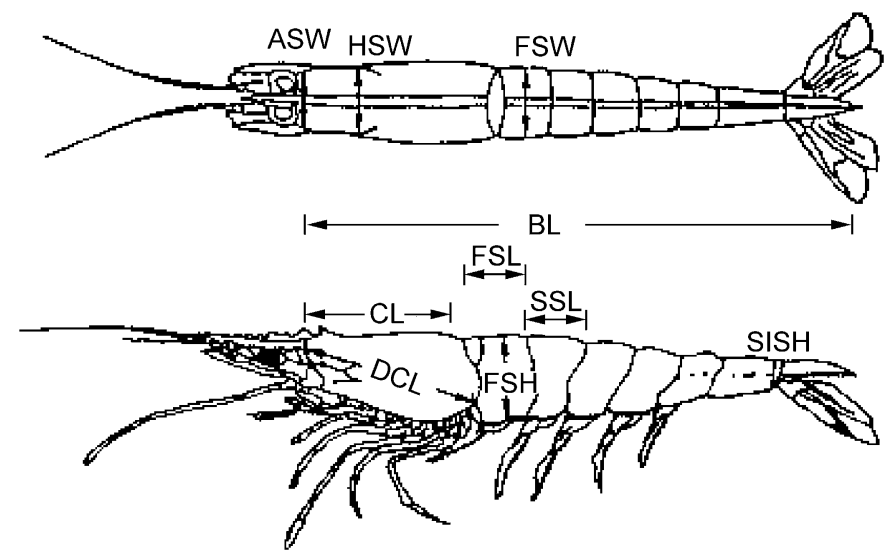

Fig. 2. M. barbata showing the body parts measured.

segment length (SSL), sixth abdominal segment height (SISH), and body length (BL). Restricting ranges of carapace length of samples to specific length classes was conducted in this study. The sample size, sampling area code, range of carapace length and relative information were shown in Table 1.

Sexual dimorphism with respect to growth in redspot prawn (Tzeng and Yeh, 1995) could result in greater variations in morphology than may be attributable to geographic variation between populations, so we used ANCOVA, with BL as the covariate, to test for differences in shape between males and females.

Burnaby's method was used to remove the effect of size variation. The resulting measurements were submitted to canonical variate analysis (CVA), and then the square of Manhattan distance (Manhattan $D^{2}$ ) between population centroids values calculated using the canonical scores. The dendrograms were constructed by three clustering methods, unweighted pair-group method with arithmetic means (UPGMA), single-link method (SINGL) and complete-link method (COMPL) by using Manhattan $D^{2}$ values (Sneath and Sokal, 1973).

The cophenetic correlation coefficient (CPCC) was estimated to measure the goodness of fit in the cluster analysis. If the CPCC value is higher, one will expect a greater degree of correspondence. The Mantel test (Mantel, 1967) was also used to determine whether the CPCC value was statistically different from zero. The number of permutations was 9999.

A randomization method (Solow, 1990) was used to detect whether the degree of discrimination between

Table 1

Sample size, sampling area, means and ranges of carapace length (CL) (mm) by sex

\begin{tabular}{|c|c|c|c|c|}
\hline Sampling area & Sex & Sample & Means of CL & Ranges of CL \\
\hline \multirow[t]{2}{*}{ Tashi } & Female & 108 & 18.60 & $15.21-23.52$ \\
\hline & Male & 105 & 16.74 & $14.34-22.17$ \\
\hline \multirow[t]{2}{*}{ Taichung } & Female & 104 & 20.95 & $16.29-23.64$ \\
\hline & Male & 102 & 18.47 & $15.12-21.02$ \\
\hline \multirow[t]{2}{*}{ Cheding } & Female & 52 & 20.45 & $17.01-23.12$ \\
\hline & Male & 69 & 18.18 & $16.18-19.79$ \\
\hline \multirow[t]{2}{*}{ Putai } & Female & 99 & 20.94 & $16.81-24.12$ \\
\hline & Male & 99 & 18.34 & $18.58-21.75$ \\
\hline \multirow[t]{2}{*}{ Keelung } & Female & 97 & 20.76 & $16.24-23.42$ \\
\hline & Male & 69 & 18.36 & $16.56-20.84$ \\
\hline
\end{tabular}


different groups in the cluster analysis arose by chance alone. All specimens were each randomly assigned to one of two groups. The new data set was then analyzed by discriminant analysis, and the resubstitution estimator (Pc) estimated (Solow, 1990). This estimator measures the proportion of individuals that are misclassified. Resampling was performed 1000 times, each with a different random permutation. This randomization procedure assesses the significance of misclassification rate by comparing the proportion of individuals (Po) that have been misclassified in the original data set to the proportion misclassified (Pc) in each random data set (Solow, 1990; Tzeng and Yeh, 1999b).

All analyses in our study were performed using Statistical Analysis System software (SAS, 1985) and NTSYS (Rohlf, 1993).

\section{Results}

The ANCOVA for differences in morphometric characters between female and male red-spot prawn (Table 2) revealed sexual dimorphism $(P<0.01)$ in eight of the nine morphometric characters. Therefore, the analyses of morphometric characters were conducted with sexes separated. Differences $(P<0.01)$ between sampling areas were observed for all nine morphometric characters. The interaction between sex and area was not significant for any of the characters except DCL character (Table 2).

See Table 3 for CPCC values of dendrograms constructed from three clustering methods based on

Table 2

Results of ANCOVA for sexual dimorphism in morphometric characters

\begin{tabular}{llll}
\hline $\begin{array}{l}\text { Morphometric } \\
\text { character }\end{array}$ & $\begin{array}{l}\text { Sex } \\
\text { effect }\end{array}$ & $\begin{array}{l}\text { Area } \\
\text { effect }\end{array}$ & $\begin{array}{l}\text { Sex } \times \text { area } \\
\text { interaction }\end{array}$ \\
\hline ASW & 0.1293 & 0.0001 & 0.0758 \\
HSW & 0.0001 & 0.0001 & 0.0255 \\
CL & 0.0001 & 0.0001 & 0.0192 \\
DCL & 0.0001 & 0.0001 & 0.0001 \\
FSL & 0.0001 & 0.0001 & 0.0959 \\
FSW & 0.0001 & 0.0001 & 0.1441 \\
FSH & 0.0001 & 0.0001 & 0.0123 \\
SSL & 0.0001 & 0.0001 & 0.4030 \\
SISH & 0.0028 & 0.0001 & 0.2033 \\
\hline
\end{tabular}

Table 3

CPCC values of dendrograms constructed from three kinds of clustering method based on female and male data sets (the results of Mantel test were also shown)

\begin{tabular}{llll}
\hline Clustering method & Data set & CPCC & $P$ \\
\hline UPGMA & Female & 0.84489 & 0.0319 \\
& Male & 0.87349 & 0.0191 \\
SINGL & Female & 0.78349 & 0.0169 \\
& Male & 0.80092 & 0.0178 \\
COMPL & Female & 0.84033 & 0.0305 \\
& Male & 0.86619 & 0.0170 \\
\hline
\end{tabular}

female and male data sets were shown. Our results revealed that the UPGMA clustering method with the highest CPCC value was the best among three clustering method employed. All CPCC values derived from UPGMA clustering method were larger than 0.8 , so the goodness of fit of our cluster analyses were high. The results of a Mantel test indicated that all CPCC values are statistically different from zero $(P<0.05)$.

All dendrograms constructed from different clustering methods showed the same result. The following dendrograms were constructed by UPGMA clustering method. Figs. 3 and 4 show dendrograms for female and male, respectively. Both results were very similar. Two major groups were observed, the first containing a population from Keelung; the second populations from Tashi, Taichung, Putai, and Cheding. Specimens from the four sampling areas in the second group were firstly pooled as a data set, and then these two data sets were used in randomization test for each sex.

The histogram of the 1000 values of the misclassification rate $(\mathrm{Pc})$ for each sex was shown in Fig. 5. The Po values in two data sets were extreme in magnitude compared with 1000 misclassification rates resulting from permuted data. These indicated that there were significant non-random structure in the data, and supported that the morphometric variation between populations from Keelung and from the other sampling areas was significant.

\section{Discussion}

Five sampling areas were clustered into two distinct groups, for each sex, demonstrating that there might 


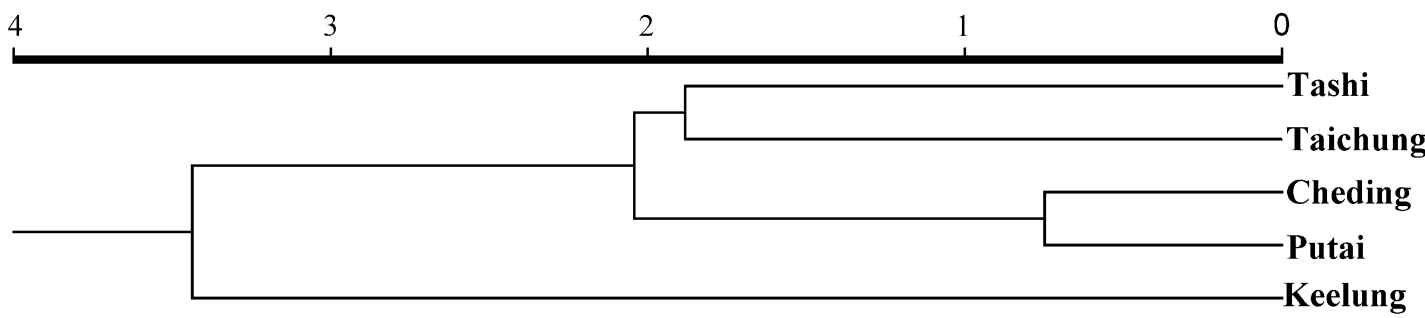

Fig. 3. Dendrogram for five sampling areas for female data set.

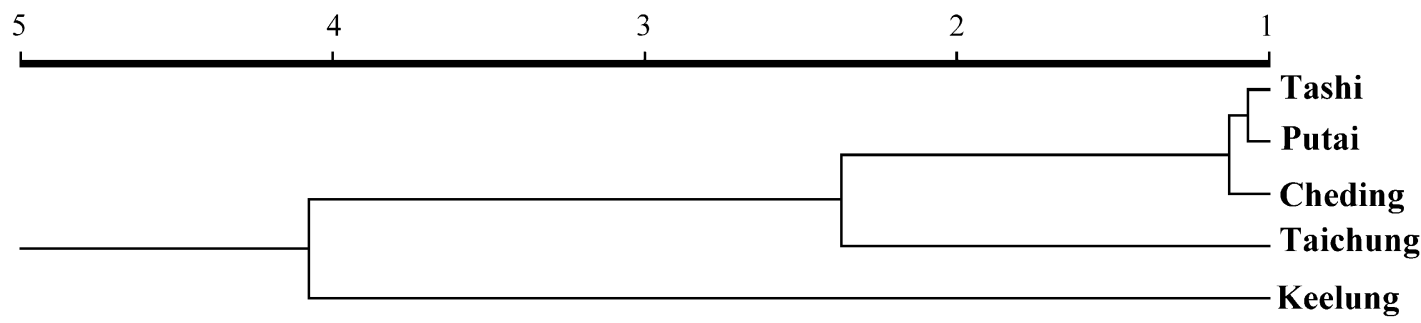

Fig. 4. Dendrogram for five sampling areas for male data set.
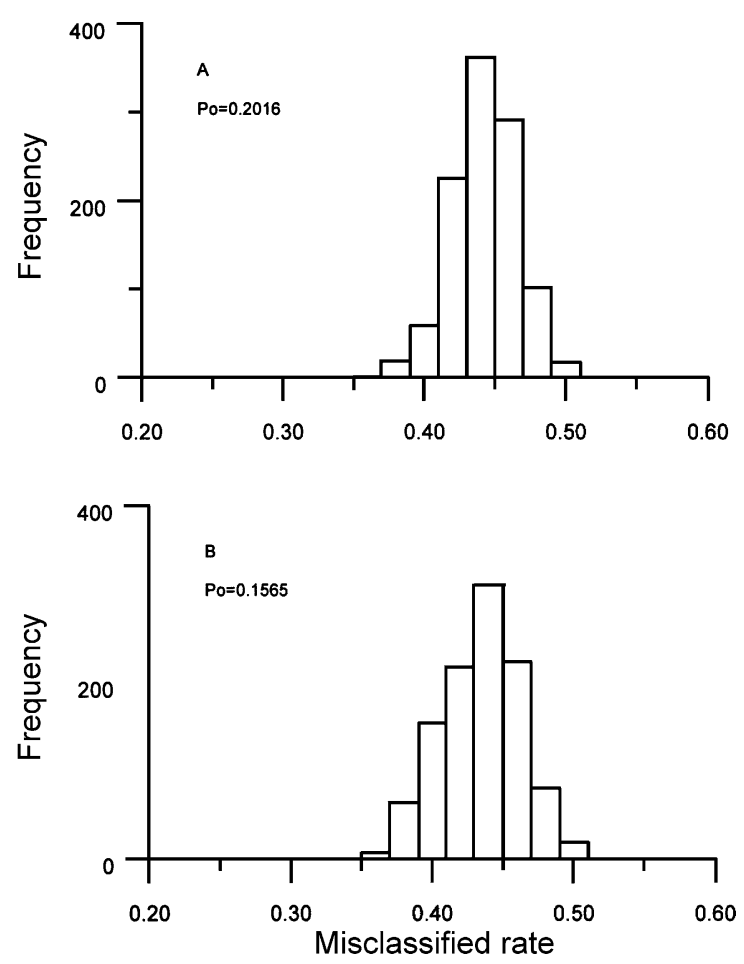

Fig. 5. Frequency distribution of 1000 misclassification rate (Pc): (A) female data, (B) male data. Po stands for the misclassification rate estimated from the original data set. be considerable morphological divergence between different geographical groups. The results of randomization testing showed that it was extremely unlikely that the extremely low misclassification rate from the original data set was due to chance alone. Therefore, if a stock is considered as an intra-specific group of individuals exhibiting unique phenotypic attributes, then, based on these results, the red-spot prawn in these waters should have two separate stocks. One stock is in the north of Keelung, the other in the Taiwan Strait and Tashi.

Sexual dimorphism, timing of sampling, allometric growth, and state of maturity may confound the analytical results of morphological relationships between geographical populations. One study attempted to minimize variances caused by these parameters through the use of size correction method, narrowing the differences of size among groups, approaching sampling times and analyzing separately by sex. However, restricting group comparisons to specific length classes may disregard ontogenetic change within groups, and the information may be necessary for meaningful descriptions of group differences (Bookstein et al., 1985). This effect may be not significant in this study, because the carapace lengths of individuals in each group were not all equal. 
Sampling areas were mostly overlaid by Kuroshio water masses, Taiwan Strait water masses, or water masses of the South China Sea in specific seasons, but the north of Keelung was also covered by the China Coastal water (Lee and $\mathrm{Hu}, 1998$ ). Differences in water masses between sampling areas may be partly responsible for the morphometric variation.

Dramatic changes in stocks may arise during short time periods, and different stocks may belong to the same taxonomic population, and thus may present large differences in their biological parameters, but not in genetic markers. Moreover, two stocks may possess significant levels of differentiation for such biological parameters, even with substantial gene flow (Marr, 1957). Such biological parameters are usually phenetic characters. Genotypic methods may deliver higher levels of resolution with greater temporal consistency, but some phenotypic studies have demonstrated variability between samples where no genotypic differentiation was found (Leslie and Grant, 1990; Roby et al., 1991). Furthermore, there are cases where differentiation at the mtDNA level is not shown at the nuclear DNA level (Ward et al., 1989; Smolenski et al., 1993); the opposite is also true (Ferguson et al., 1991). Therefore, the power to discriminate stocks depends on the selection of analytical method, and several approaches, employed simultaneously, are often beneficial.

Variation of morphometric characters may be affected by genetic and environmental factors. Thus, phenetic differences between examined populations may reflect either genetic differences between the stocks or environmental differences between localities. Therefore, discrimination of stocks based on morphometric variation must be verified by genetic evidence to confirm that the former differences reflect some degree of reproductive isolation rather than simply environmental distinctness (Pepin and Carr, 1992). Unless specific characters are known to have a genetic basis, the use of multivariate analysis of a set of phenotypic characters to separate stocks or determine morphological relationships between populations is regarded as a more appropriate method (Thorpe, 1983).

We used several multivariate morphometric characters to examine the stock structure of red-spot prawn in adjacent waters off Taiwan and produced moderate resolution, but further verification of this outcome is required.

\section{Acknowledgements}

We would like to express appreciation to our staff, Demersal Research Center, Institute of Oceanography, National Taiwan University, for assistance in collecting samples and preparing drawings.

\section{References}

Avsar, D., 1994. A stock differentiation study of the sprat (Sprattus sprattus phalericus Risso) off the southern coast of the Black Sea. Fish. Res. 19, 363-378.

Bookstein, F.L., Chernoff, B., Elder, R.L., Humphries, J.M., Smith, G.R., Strauss, R.E., 1985. Morphometrics in Evolutionary Biology: The Geometry of Size and Shape Change with Examples from Fishes. Special Publication No. 15. Academy of National Sciences, Philadelphia, PA, 277 pp.

Burnaby, T.P., 1966. Growth-invariant discriminant functions and generalized distance. Biometrics 22, 96-110.

Ferguson, M.M., Danzmann, R.G., Hutchings, J.A., 1991. Incongruent estimates of population differentiation among brook charr, Salvelinus fontinalis, from Cape Race, Newfoundland, Canada, based upon allozyme and mitochondrial DNA variation. J. Fish Biol. 39, 79-85.

Humphries, J.M., Bookstein, F.L., Chernoff, B., Smith, G.R., Elder, R.L., Poss, S.G., 1981. Multivariate discrimination by shape in relation to size. Syst. Zool. 30, 291-308.

Lee, I.H., Hu, J.H., 1998. The relation between the I-Lan bight water and the shelf water northeast of Taiwan. Acta Oceanogr. Taiwanica 37 (1), 89-103.

Leslie, R.W., Grant, W.S., 1990. Lack of congruence between genetic and morphological stock structure of the Southern African anglerfish Lophius vometinus. S. Afr. J. Mar. Sci. 9, 379-398.

Mantel, N.A., 1967. The detection of disease clustering and a generalized regression approach. Cancer Res. 27, 209-220.

Marr, J.C., 1957. Contributions to the study of subpopulations of fishes. Spec. Sci. Rep. Fish. 208. US Fish and Wildlife Service, $129 \mathrm{pp}$.

Moritz, C., Dowling, T.E., Brown, W.M., 1987. Evolution of animal mitochondrial DNA: relevance for population biology and systematics. Ann. Rev. Ecol. Syst. 18, 269-292.

Pepin, P., Carr, S.M., 1992. Morphological, meristic, and genetic analysis of stock structure in juvenile Atlantic cod (Gadus morhua) from the Newfoundland shelf. Can. J. Fish. Aquat. Sci. 50, 1924-1933.

Reist, J.D., 1985. An empirical evaluation of coefficients and used in residual and adjustment of size covariation. Can. J. Zool. 64, 1363-1368.

Roby, D., Lambert, J.D., Sevigny, J.M., 1991. Morphometric and electrophoretic approaches to discrimination of capelin (Mallotus villosus) population in the Estuary and Gulf of St. Lawrence. Can. J. Fish. Aquat. Sci. 48, 2040-2050.

Rohlf, F.J., 1993. NT-SYS, Numerical Taxonomy and Multivariate Analysis System. Exeter Software. 
SAS, 1985. SAS User's Guide, Statistics. SAS Institute, Inc., Carry, NC.

Shaklee, J.B., Tamaru, C.S., Waples, R.S., 1982. Speciation and evolution of marine fishes studied by the electrophoretic analysis of protein. Pac. Sci. 36, 141-157.

Smolenski, A.J., Ovenden, J.R., White, R.W.G., 1993. Evidence of stock separation in southern hemisphere orange roughy (Hoplostethus atlanticus, Trachichtyidae), from restriction enzyme analysis of mitochondrial DAN. Mar. Biol. 116, 219230.

Sneath, P.H.A., Sokal, R.R., 1973. Numerical Taxonomy. Freeman, San Francisco, CA, 573 pp.

Solow, A.R., 1990. A randomization test for misclassification probability in discriminant analysis. Ecology 71, 23792382.

Thorpe, R.S., 1983. A biometric study of the effects of growth on the analysis of geographical variation: tooth number in Green geckos (Reptilia: Phelsuma). J. Zool. 201, 13-26.

Tzeng, D.D., Yeh, S.Y., 1995. Growth parameters of red-spot shrimp, Metapenaeopsis barbata, from the adjacent waters off Taichung harbor. J. Fish. Soc. Taiwan 22 (1), 53-68.
Tzeng, T.D., Yeh, S.Y., 1999a. Analysis of the morphometric characters of kuruma shrimp (Penaeus japonicus) in the East China Sea and the Taiwan Strait. J. Fish. Soc. Taiwan 26 (4), 203-212.

Tzeng, T.D., Yeh, S.Y., 1999b. Permutation tests for difference between two multivariate allometric patterns. Zool. Stud. 38 (1), 10-18.

Tzeng, D.D., Chiu, C.S., Yeh, S.Y., 1998. Comparison of multivariate allometric coefficients in red-spot prawn (Metapenaeopsis barbata) from adjacent waters off Taiwan. J. Fish. Soc. Taiwan 25 (2), 85-92.

Waldman, J.R., Grossfield, J., Wrigin, I., 1988. Review of stock discrimination techniques for striped bass. N. Am. J. Fish. Mgmt. 8, 410-425.

Ward, R.D., Billington, N., Hebert, P.D.N., 1989. Comparison of allozyme and mitochondrial DNA variation in populations of walleye, Stizostedion vitreum. Can. J. Fish. Aquat. Sci. 46, 2074-2084.

Wu, C.C., 1984. Survey of shrimp in Taiwan Strait and biological studies of thick shell shrimp (Metapenaeopsis barbata). Bull. Taiwan Fish. Res. Inst. 37, 67-82. 